\title{
Spirituality and Spiritual Care among Ethnic Chinese Residing in England: Implications for Nursing
}

\author{
Yanping Niu ${ }^{1,2, *(\mathbb{D}}$, Wilfred McSherry $\left.{ }^{2,3,4} \mathbb{(}\right)$ and Martin Partridge ${ }^{5}(\mathbb{C}$ \\ 1 Department of Nursing, Changzhi Medical College, Changzhi 046000, China \\ 2 Department of Nursing, School of Health and Social Care Staffordshire University, Stoke-on-Trent ST4 2DE, \\ UK; W.McSherry@staffs.ac.uk \\ 3 School of Health, Science and Wellbeing, The University Hospitals of North Midlands NHS Trust, \\ Stoke-on-Trent ST4 6QG, UK \\ 4 Fakultet for Helsefag, VID Specialized University, NO-0319 Oslo, Norway \\ 5 Faculty of Education Health \& Wellbeing, University of Wolverhampton, Wolverhampton WV1 1LY, UK; \\ M.Partridge@wlv.ac.uk \\ * Correspondence: y.niu@czmc.edu.cn
}

Citation: Niu, Yanping, Wilfred McSherry, and Martin Partridge. 2021. Spirituality and Spiritual Care among Ethnic Chinese Residing in England: Implications for Nursing. Religions 12: 887. https://doi.org/10.3390/ rel12100887

Academic Editor: Christian Zwingmann

Received: 15 September 2021

Accepted: 10 October 2021

Published: 15 October 2021

Publisher's Note: MDPI stays neutral with regard to jurisdictional claims in published maps and institutional affiliations.

Copyright: (c) 2021 by the authors. Licensee MDPI, Basel, Switzerland. This article is an open access article distributed under the terms and conditions of the Creative Commons Attribution (CC BY) license (https:// creativecommons.org/licenses/by/ $4.0 /)$.

\begin{abstract}
Background: There is a lack of understanding of how spirituality is understood among ethnic Chinese living outside of China. The aim of this investigation was to gain insight into the meaning of spirituality and spiritual care among ethnic Chinese residing in England. (2) Methods: This study employed a grounded theory method. (3) Results: A core category called "seeking a meaningful life" emerged, comprising six categories: "motivation", "support", "maintaining standard values", "achieving a meaningful life", "relationships" and "perceptions of spirituality". The core category included a three-stage process influenced by two factors: relationships with others and perceptions of spirituality. In motivated or supported situations of suffering and illness, ethnic Chinese usually follow principles of their Chinese tradition in seeking meaning for a satisfied spiritual life. This process is impacted by their relationships with others and view of spirituality. (4) Conclusions: Participants' understanding of spirituality and spiritual care was related to seeking meaning and purpose in life. Nurses could incorporate the newly developed life meaning processes into their practice. This could be achieved by culturally explaining suffering and focusing on the significance of physical illness for Chinese people. This would ensure their spiritual care practice delivers culturally competent care for ethnic Chinese. Educators could also incorporate this process within their teaching materials so that this aspect of spiritual care is addressed for this specific group.
\end{abstract}

Keywords: ethnic; Chinese; grounded theory; health; nursing; spirituality; spiritual care

\section{Introduction}

Spirituality and spiritual care are fundamental to people's health (International Council of Nurses (ICN 2012)). Patients' attitudes to spirituality influence their behavior to prevent illness (Nair et al. 2021). Ethnic Chinese is one of the largest Asian sub-groups in the UK and the population has doubled in the last 10 years (GOV.UK 2020). They have specific spiritual and cultural beliefs which may impact their overall health (Speed et al. 2021; Niu et al. 2020). This study explored how ethnic Chinese residing in England perceive spirituality and spiritual care to help nurses respond to their cultural and religious needs. Ethnic Chinese refers to people residing in the UK who deem themselves to have Chinese roots, for example, those from mainland China, Taiwan, Hong Kong or Singapore.

Spirituality has been described as a multi-dimensional concept, including one's relationship with God (Carson and Stoll 2009), the meaning and purpose of life (Murray and Zentner 1989), holistic manifestation in physical-social-spiritual strength (Narayanasamy 1999), humanity (Puchalski et al. 2014) and transcendence (McSherry et al. 2021). This indicates that over the past two decades within healthcare and nursing, the definitions of 
spirituality have advanced from an atheistic and religious perspective to a more general approach combining religious and non-religious understandings (Swinton 2010), and then to a secular or atheistic understanding incorporating humanistic concern of people's values and traditions and existential searches in finding meaning and relations. The development of the definitions also shifted from a religious to a holistic view of health which incorporates the physical, psychological, social and spiritual or religious aspects of human beings. This emphasizes the role of spirituality in people's overall health. The importance of values and traditions in understanding spirituality and the places of spirituality in people's overall health shows that people from different cultural backgrounds may have different spiritual needs for improving their health and life quality. A recent study shows that the holistic care considering people's cultural beliefs and values was used less among the healthcare users of ethnic groups in the UK (de Vries et al. 2019). This highlights the importance of understanding spirituality and spiritual care among Chinese and other ethnic groups.

Ethnic Chinese are highly spiritual; spirituality in Chinese, jingshen (精神) or lingxing (灵性), linguistically means "state of mind" and "spirit", respectively (Chinese Academy of Social Science 2016). Jingshen is closely associated with the three main concepts of jing, Qi, and shen, originating from Daoism and traditional Chinese medicine, indicating essence, driving forces and vitality of life (Chen et al. 2008). With language development and the living context changing, spirituality may have new meaning in healthcare where an individual's beliefs, values and existential concerns about health are weaved together.

There is a lack of up-to-date definitions of spirituality in the Chinese context, for example, in the Chinese diasporic community or Chinese healthcare settings, and very few studies explaining how spirituality can help ethnic Chinese to deal with illness (Mok et al. 2010) and how these concepts are associated with the relationship with the self, others, nature and Higher Being(s) (Chao et al. 2002). A limitation of the few studies that do exist is that they originate from Hong Kong and Taiwan, where there has been a significant Western influence. It is therefore unclear whether these definitions reflect understandings of people from mainland China who may hold different personal and spiritual beliefs influenced by atheist philosophy (Niu et al. 2021a; Zhu and Wong 2021). This highlights the need for a study that could provide a comprehensive understanding of spirituality and spiritual care among different ethnic Chinese populations residing in the UK.

A definition of spiritual care is rarely provided in the healthcare literature. The one that has been most frequently cited is the one written by NHS Education for Scotland (2009) which suggests that spiritual care is the response to the needs of the human spirit in ill health, including the need for meaning, self-worth and faith in compassionate relationships addressing whatever is required. This is consistent with the above definition of spirituality provided by Glenn and Pieper (2019) and recognizes the importance of support for individuals as they seek life meaning, adhering to self-values and faith to obtain a sense of transcendence in their relationships with others and God.

This investigation aims to gain insights into the meaning of spirituality and spiritual care among ethnic Chinese residing in England, where the majority of the UK's ethnic Chinese reside.

\section{Method}

The Straussian school of grounded theory (Strauss and Corbin 1998) was used to guide this investigation, offering a flexible yet rigorous approach to explore how knowledge of spirituality and spiritual care is understood by ethnic Chinese. It was shown that understanding these subjective concepts can only emerge when researchers actively interact with participants through the exploration of language and utilization of different forms of communication. 


\subsection{Participant Selection}

Participants were selected from four Chinese community centers in the three cities where most ethnic Chinese reside: Birmingham (12,712) (two centers), Manchester $(13,539)$ and London $(124,250)$ (GOV.UK 2020).

The primary researcher contacted managers in Chinese community centers by email, phone and in-person to provide an overview of the investigation, describing their role in the recruitment phase. This included identifying participants according to the set inclusion criteria, introducing the project to them, and setting dates and venues for the interview. The inclusion criteria were: being 18 years old or above; being ethnic Chinese; residing in the UK at the time of recruitment. Participants had no cognitive or mental impairment diagnosed by a doctor or known to the managers at the time of the interview. The primary researcher was a registered nurse of Chinese nationality completing her $\mathrm{PhD}$ research in nursing. She was trained in interview skills before data collection and the two co-authors, who were experienced qualitative researchers, supervised her PhD journey and verified the data collection and analysis process.

\subsection{Recruitment}

The first six participants were recruited through purposive sampling based on the inclusion criteria. Subsequently, 19 participants were recruited using theoretical sampling, based on the emerging concepts developed from the previous interview (Corbin and Strauss 2015). This meant that participants were recruited due to specific demographic requirements or because it was felt they may possess specific knowledge or beliefs that may further develop the emerging theory.

After theoretical saturation was reached when there was no new emergent information, recruitment stopped and the community center managers were notified.

Recruitment was conducted from February 2015 to October 2016, and the primary researcher contacted the managers of Chinese community centers. During the recruitment process, two potential participants from China refused to take part: one worried that the interview was going to be recorded and the researcher may explore some political matters; the other directly cut ties with the primary researcher after interacting with her for a few weeks without giving a reason. About five potential participants refused to let the primary researcher approach them. The recruitment process was voluntary and the researcher had no direct influence on it.

\subsection{Interview}

The primary researcher collected and analyzed data from July 2015 to October 2016 to allow see what patterns emerge, and then constructed and verified theory with participants till 2018.

Twenty-four in-depth interviews (one couple preferred to be interviewed together) were conducted in places convenient for the participants, such as rooms in the Chinese community centers, participants' own homes or a quiet area in a library. As eight participants spoke Cantonese and Hakka, four professional interpreters working in the community center were hired after signing a confidentiality agreement. The interpreters were fluent in these dialects and Mandarin, facilitating communication between the participants and the researcher. The conversations being conducted in Chinese, which was the native language of the participants, interpreters and interviewers, allowed linguistic nuances to be identified (Clark et al. 2017). The interviews lasted between 30 and $60 \mathrm{~min}$ and a digital recorder was used to record them. During the interviews, several participants also provided some keywords by writing Chinese characters to facilitate the researcher's understanding. Upon completion, participants were requested to complete a demographic form. This was to provide some contextual information about the participants and support the analysis, and field notes were also taken.

An interview agenda was used to guide the interview. The initial research questions used to guide the discussion were "What does spirituality mean to you?" and "What does 
spiritual care meant to you?". Two additional questions were used: "What is your life perception?" or "What is significant to you?" (Balthip et al. 2017) if participants struggled when addressing the first two questions. In addition to the open questions, theoretical questions were also used to advance the emerging concepts. For example, when deathrelated suffering appeared as an understanding of spirituality, the question "What other sufferings could also be considered as spirituality?" was used to develop the concept of suffering. Likewise, "What should nurses do to support patients?" was used to advance understanding when suffering from illness emerged.

\subsection{Transcription and Translation}

The primary researcher was a native Chinese speaker and competent in English since she had been employed in English-speaking organizations for more than a decade. After repeatedly listening to the recordings sentence by sentence (line by line) and clarifying any ambiguity that arose with the interpreters, she transcribed each interview and invited an academic to verify the transcript considering that the majority of participants were old and so there were difficulties in creating the transcripts. The academic held a position at Staffordshire University and was fluent in Mandarin and Cantonese and able to identify the linguistic difference between the recording and transcript by listening to the recording and looking at the transcript. After transcription, the transcripts were translated from Chinese to English by the primary researcher and verified by the same academic who was also fluent in English so that the study could be guided by the co-authors. Conducting the interviews in Chinese and having the primary researcher carrying out the interviews, transcription and translation assured the translation-equivalency of this study (Clark et al. 2017). The translated data were then input into the NVivo11 software, ready for analysis.

\subsection{Data Analysis}

The coding process and development of concepts were conducted by the primary researcher and then examined and verified by the co-authors in a group once a week to reach a consensus for any disagreement.

Data analysis utilized Strauss and Corbin's grounded theory strategies (Strauss and Corbin 1998) for open, axial and selective coding. In open coding, line-by-line labelling of the transcripts and grouping of the labels with similar meanings led to the creation of second or upper-level codes. Codes with similar connotations were then categorized under a category and this category may become a dimension or property of an upper-level concept. For example, the lower-level labels health problems and family problems were grouped under the category suffering because these were issues related to grieving experiences. Axial coding was used to relate a category to its sub-categories by applying the coding paradigm of condition, action and consequence in Straussian grounded theory (Strauss and Corbin 1998) in the open, axial, and selective coding stages of data analysis. For example, the concept of suffering demonstrated a phenomenon that in a problematic situation, individuals act differently and this can have a different impact on one's life. In this situation, health problems and family problems were conditions affecting the participants; attitude to suffering is the action taken when facing such a situation. No concept was developed for consequence as different actions implied the consequence if one was in a suffering context.

Selective coding was used to select or derive a central category seeking a meaningful life by unifying the six emergent categories using axial coding and story-telling techniques (Niu 2019). In this stage, the sub-categories suffering, need and hope were grouped under "motivation" since participants' suffering experience, their need and hope for a better life may motive them to seek meaning in life. Additionally, the supporting resources gained in the healthcare setting and in daily life in the aspects of communication, compassionate care and religious support made this possible. The motivation and supporting resources were then put together as conditional factors for seeking life meaning action: "adhering to standard values" in cultural and religious traditions of Confucianism, Daoism and Buddhism. This action led to the outcome of adhering to the standard values of "achieving a meaningful life" 
to gain different levels of contentment or joy, attain happiness, an internal force, and grasp the essence and nature of life. The contextual categories, "relationships" with self and others and "perceptions of spirituality" could influence this process. The paradigm of condition, action, consequence and context categories are presented in Figure 1.

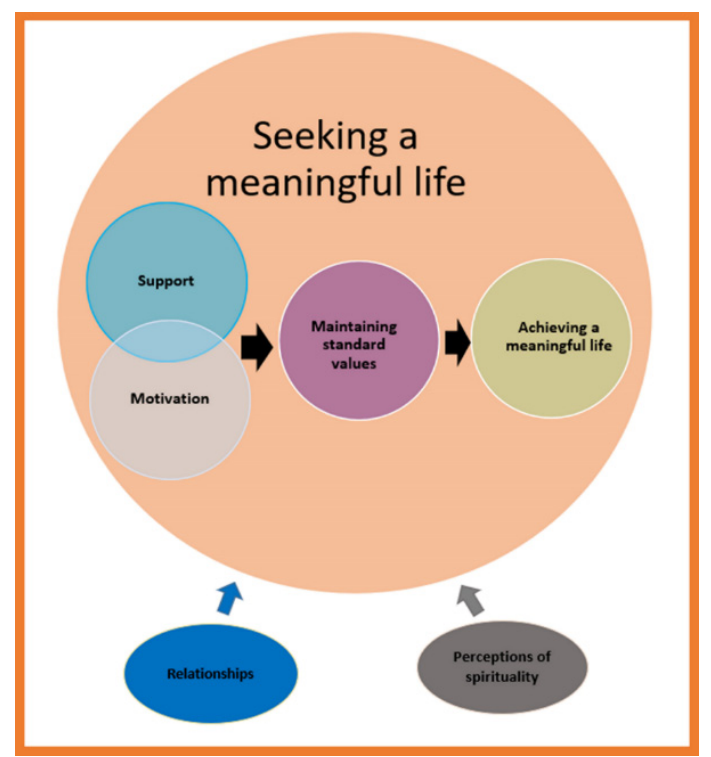

Figure 1. The core category seeking a meaningful life. Frame: the core category seeking a meaningful life; large circle: the three-stage process, with the small circles indicating condition, action and consequences and arrows for the direction of the process; oval: the contextual categories, with two arrows for supporting and intervening factors.

Selective coding is a continuously evolving process, as shown in the diagram outlined in Figure 1, and story-telling strategies, as described above, complement each other to allow the core category to emerge. This is because an unsound diagram may not allow the story to flow. For example, "Chinese values" were once written as conditions and "spiritual resource" and "spiritual care" as actions in a diagram to achieve a meaningful life. This was based on the primary author's intuitive thought that "Chinese cultural values" were the source and context, and "spiritual care", together with "spiritual resource", was an action for "seeking a meaningful life". However, this initial thought was blocked when writing the storyline since "good communication" and "caring with love" in "spiritual care" are insufficient actions with regard to enabling participants to seek and eventually achieve their life meanings. As a result, "Chinese values" were relabelled as an action "adhering to standard values", and this adjustment enabled the writing flow.

The overall coding process was an inductive analysis since this investigation generated a theory of "seeking a meaningful life" to explain Chinese participants' understanding of spirituality and spiritual care. However, an inductive-deductive approach was applied throughout the analysis to allow a general idea to emerge in the coding. This idea was further checked against the data and literature through constant comparisons and was developed in different dimensions and with different properties.

During the data analysis, memos were written to record and direct the analytical process.

\subsection{Rigor}

The authors followed Cooney's (2011) criteria, which were derived from Straussian grounded theory and are easy to follow, to establish rigor for this study in terms of credibility, auditability and fittingness. Credibility was achieved through participants freely describing their thoughts about spirituality and spiritual care, with the researchers constantly comparing the emerging concepts against the emerging terms and using the 
participants' own words as codes. The researcher also ensured credibility by remaining reflexive, articulating her insights regarding spirituality and how she utilized the literature in a reflective diary to limit her influence on the data and restrict her interpretations from the existing literature on other cultures. Auditability was gained through asking questions, such as "What is happening in the data?" and "What does the action in the data represent?" and specifying how and why participants were selected, to ensure the data analysis and collection were transparent. For example, one participant was selected because she was thought to be describing spirituality and spiritual care from an existential perspective after explaining the first six the terms from a religious perspective. Fittingness was ensured by delineating participants, the setting, the level of theory generated, and the integration of literature pertaining to each category as the theory emerged, providing other researchers with references to enable them to use the findings that emerge from this study.

\subsection{Ethics}

The investigation was approved by the Staffordshire University ethics committee. Participants were informed orally and in writing that they were free to withdraw. Their anonymity was ensured by using synonyms during interviews and in publications. They were advised that their information would be stored in a secure file for 10 years and then destroyed. The researcher gained participants' written informed consent before the interviews commenced.

\section{Participants' Characteristics}

Twenty-five $(n=25)$ ethnic Chinese participants were recruited: 11 males and 14 females, aged between 21 and 82 years (see Table 1). Participants came from Taiwan, Hong Kong, mainland China and Vietnam, and they stated their ethnicity as Han, Hakka, Hui, Man and She. Fourteen stated that they had an affiliation to Buddhism or Christianity. Ten described themselves as atheists or having belief in a blend of philosophies. The participants had resided in the UK for between six months and 30 years. Six worked in health-related sectors, three had experience of working in hospitals and four had been admitted to hospitals in the 12 months leading up to the study. 
Table 1. Participants' demographic information.

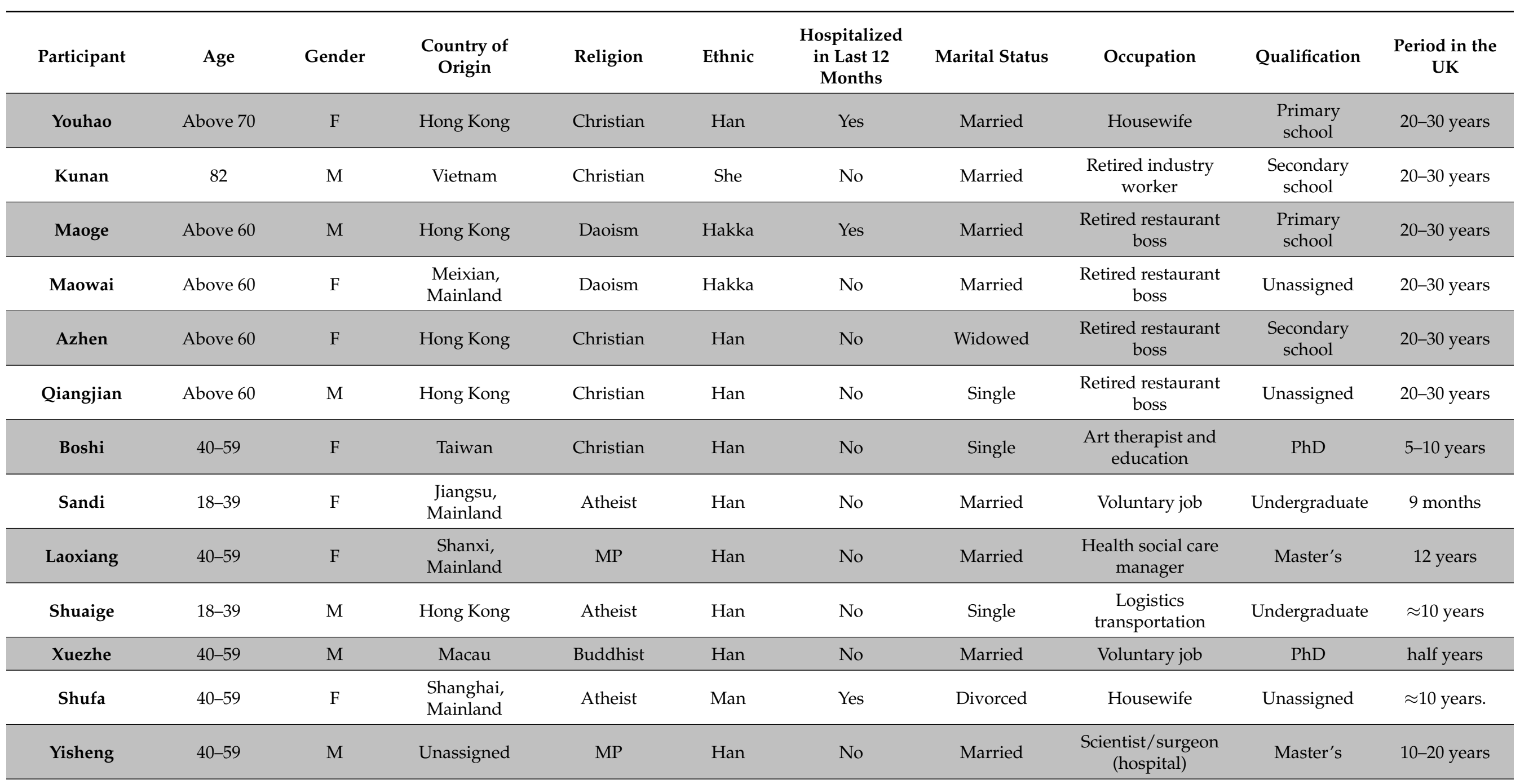


Table 1. Cont.

\begin{tabular}{|c|c|c|c|c|c|c|c|c|c|c|}
\hline Participant & Age & Gender & $\begin{array}{l}\text { Country of } \\
\text { Origin }\end{array}$ & Religion & Ethnic & $\begin{array}{l}\text { Hospitalized } \\
\text { in Last } 12 \\
\text { Months }\end{array}$ & Marital Status & Occupation & Qualification & $\begin{array}{c}\text { Period in the } \\
\text { UK }\end{array}$ \\
\hline Xieguang & $40-59$ & $\mathrm{~F}$ & $\begin{array}{l}\text { Guangzhou, } \\
\text { Mainland }\end{array}$ & Daoism & Han & No & Married & $\begin{array}{c}\text { Housewife/health } \\
\text { related }\end{array}$ & High school & $\approx 10$ years \\
\hline Wangxing & $40-59$ & $\mathrm{~F}$ & $\begin{array}{l}\text { Liaoning, } \\
\text { Mainland }\end{array}$ & $\begin{array}{c}\text { Atheist and } \\
\text { MP }\end{array}$ & Han & No & Married & $\begin{array}{l}\text { Housewife/health } \\
\text { related }\end{array}$ & High school & $\approx 10$ years \\
\hline Maipian & $40-59$ & M & $\begin{array}{l}\text { Fujian, } \\
\text { Mainland }\end{array}$ & $\begin{array}{l}\text { Communist } \\
\text { and MP }\end{array}$ & Han & No & Married & Restaurant worker & $\begin{array}{l}\text { Secondary } \\
\text { school }\end{array}$ & 12 years \\
\hline Aiwa & $40-59$ & $\mathrm{~F}$ & Hong Kong & Buddhist & Han & Yes & Married & $\begin{array}{c}\text { Taking care of } \\
\text { elderly }\end{array}$ & $\begin{array}{l}\text { Primary } \\
\text { school }\end{array}$ & 10 years \\
\hline Linde & $40-59$ & $\mathrm{~F}$ & Hong Kong & MP & Han & No & Married & $\begin{array}{l}\text { Retired restaurant } \\
\text { boss }\end{array}$ & $\begin{array}{l}\text { Primary } \\
\text { school }\end{array}$ & $\approx 10$ years \\
\hline Qinlao & $40-59$ & $\mathrm{~F}$ & $\begin{array}{l}\text { Henan, } \\
\text { Mainland }\end{array}$ & Christian & Hui & No & Married & Nurse (hospital) & Bachelor's & 15 years \\
\hline Chengshi & $18-39$ & M & $\begin{array}{l}\text { Henan, } \\
\text { Mainland }\end{array}$ & Muslim & Hui & No & Single & $\begin{array}{c}\text { Care assistant } \\
\text { (hospital) }\end{array}$ & College & $\approx 10$ years \\
\hline Heping & $40-59$ & M & Hong Kong & Christian & Han & No & Married & Social worker & $\mathrm{PhD}$ & $>30$ years \\
\hline Dianxin & Above 60 & M & Taiwan & $\mathrm{MP}$ & Han & No & Married & Retired & Undergraduate & $\approx 30$ years \\
\hline Xiaojin & $18-39$ & M & $\begin{array}{l}\text { Guangzhou, } \\
\text { Mainland }\end{array}$ & $\begin{array}{c}\text { Atheist, } \\
\text { Agnostic, and } \\
\text { MP }\end{array}$ & Han & No & Single & Student & $\begin{array}{c}\text { In undergrad- } \\
\text { uate } \\
\text { program }\end{array}$ & 12 years \\
\hline Pengchao & $18-39$ & $\mathrm{~F}$ & $\begin{array}{l}\text { Hunan, } \\
\text { Mainland }\end{array}$ & $\mathrm{MP}$ & Han & No & Single & Student & Master's & 2 years \\
\hline Mimang & $18-39$ & $\mathrm{~F}$ & $\begin{array}{l}\text { Meixian, } \\
\text { Mainland }\end{array}$ & $\begin{array}{c}\text { Christian and } \\
\text { Buddhist }\end{array}$ & Hakka & No & Single & Student & High school & 3 years \\
\hline
\end{tabular}

F: female; M: male; $\approx$ : about; >: more than; MP: Mixed Philosophy. 


\section{The Three-Stage Process: Seeking a Meaningful Life}

Participants provided their understanding of spirituality and spiritual care from a Chinese cultural and devotional perspective. This was integrated into a core category, seeking a meaningful life, consisting of six categories: "motivation", "support", "maintaining standard values", "achieving a meaningful life", "relationships" and "perceptions of spirituality" (see Table 2), following a three-stage process. Being in a motivating and supported situation, the ethnic Chinese in this study used principles of Chinese traditions to seek their life meanings. Their "relationships" with others and perceptions of spirituality can influence this process (see Figure 1). In terms of seeking life meaning, Laoxiang defined spirituality as the meaning and purpose of life, and Wangxing stated that spirituality was the purpose and meaning of life in this world, in response to "what is spirituality?".

"Well, that is about the understanding of the term jingshen (精神), which is spirituality in English. I have just talked about it. I think it is important to orientate the overall meaning of life either consciously or subconsciously." (Laoxiang)

“We now have a clear understanding with this spirituality (灵性). What is the purpose of our existence in this world? I started to understand now." (Wangxing)

In the following, the authors describe the main stages, together with the sub-categories, supporting excerpts and participants' pseudonyms.

Additional supporting quotes are also presented in Table 3 . These can be traced by referring to the participant's pseudonyms in the text and Table 3 in the related sections.

Table 2. Core category, categories and sub-categories.

\begin{tabular}{|c|c|c|}
\hline Core Category & Category & Sub-Category \\
\hline \multirow{4}{*}{$\begin{array}{l}\text { Seeking a meaningful life } \\
\text { (Contextual category) } \\
\text { Relationships } \\
\text { Perceptions of spirituality }\end{array}$} & Motivation & $\begin{array}{l}\text { Suffering } \\
\text { Need } \\
\text { Hope }\end{array}$ \\
\hline & Support & $\begin{array}{l}\text { Spiritual resource } \\
\text { Spiritual care }\end{array}$ \\
\hline & Maintaining standard values & $\begin{array}{c}\text { Chinese culture } \\
\text { Religion }\end{array}$ \\
\hline & Achieving a meaningful life & $\begin{array}{c}\text { Happiness } \\
\text { Driving forces } \\
\text { Essence and nature of life }\end{array}$ \\
\hline
\end{tabular}


Table 3. The elements of the core category and example quotations.

\begin{tabular}{|c|c|c|c|c|}
\hline Category & Sub-Category & Extract & Authors' Explanation & Participant \\
\hline \multirow{9}{*}{ Motivation } & \multirow{4}{*}{ Suffering } & "I was very scared while I was bleeding." & Maoge related spirituality to anxiety in a health crisis. & Maoge \\
\hline & & $\begin{array}{l}\text { "I am very worried that my deterioration will affect my } \\
\text { children." }\end{array}$ & $\begin{array}{l}\text { Aiwa was worried about her illness bothering families } \\
\text { when addressing spirituality. }\end{array}$ & Aiwa \\
\hline & & $\begin{array}{l}\text { "They liked to eat some Chinese food and they liked the family } \\
\text { to send some food for them, (such as) soup, or something. They } \\
\text { cannot get used to hospital food." }\end{array}$ & $\begin{array}{l}\text { Suffering triggered by material or service desire were } \\
\text { illustrated by Qinlao, saying that patients were } \\
\text { distressed at being unable to eat Chinese food daily } \\
\text { when hospitalized. }\end{array}$ & Qinlao \\
\hline & & $\begin{array}{l}\text { "It is really like the saying in the classic Chinese that when } \\
\text { Heaven is going to give great responsibility to a human, it must } \\
\text { bitter his heart and will, make him hungry, exhaust his muscles } \\
\text { and bones ... I really believe the saying and I think it is } \\
\text { reasonable." }\end{array}$ & $\begin{array}{l}\text { Pengchao stated that a person has to accept the } \\
\text { suffering and let it be, since it is a prelude to success } \\
\text { and can enhance their tolerance. }\end{array}$ & Pengchao \\
\hline & \multirow{3}{*}{ Need } & $\begin{array}{l}\text { "He had lied to me about his profession. Since he had no a } \\
\text { stable job, he knew that I would not have developed my } \\
\text { relationship with him if he had told me the truth." }\end{array}$ & $\begin{array}{l}\text { Sandi highlighted that a job is important for a } \\
\text { sustainable life. }\end{array}$ & Sandi \\
\hline & & $\begin{array}{l}\text { "You can go to the Chinese association where the Chinese get } \\
\text { together to find and make new friends who have the same } \\
\text { interests. Then, you will live very well." }\end{array}$ & $\begin{array}{l}\text { Dianxin stated that spirituality was his need for } \\
\text { interaction with a Chinese community. }\end{array}$ & Dianxin \\
\hline & & $\begin{array}{l}\text { “You need the treasure guider and guarantor (引宝师) to bring } \\
\text { you to seek Dao (way of heaven, being human and life in } \\
\text { Daoism, 道)." }\end{array}$ & $\begin{array}{l}\text { Maowai associated spirituality with the need for } \\
\text { spiritual guidance in following a particular way of life. }\end{array}$ & Maowai \\
\hline & \multirow{2}{*}{ Hope } & $\begin{array}{l}\text { "Um ... there is certainly ... um ... a pursuit in a person's } \\
\text { deep heart. It is a spiritual sustenance in a person's deep heart. } \\
\text { It can also be a kind of desire." }\end{array}$ & $\begin{array}{l}\text { Participant showed that spirituality and spiritual care } \\
\text { are the hope and pursuit in one's heart. }\end{array}$ & Mimang \\
\hline & & "(I hope the) a gift of good health (from God)." & $\begin{array}{l}\text { In response to the question "Could you say something } \\
\text { about hope?", Azhen expressed her hope for the "gift } \\
\text { of good health". }\end{array}$ & Azhen \\
\hline
\end{tabular}


Table 3. Cont.

\begin{tabular}{|c|c|c|c|c|}
\hline Category & Sub-Category & Extract & Authors' Explanation & Participant \\
\hline \multirow{6}{*}{ Support } & \multirow[t]{2}{*}{ Spiritual resource } & $\begin{array}{l}\text { "When you have a development opportunity at work, your } \\
\text { support from your own experience and your colleagues is } \\
\text { important. As for a younger person, parental support and peer } \\
\text { support are important. Otherwise, I think many people will } \\
\text { withdraw." }\end{array}$ & $\begin{array}{l}\text { Participants related their understanding of spirituality } \\
\text { and spiritual care to the different forms of support } \\
\text { available in everyday life. For example, Laoxiang } \\
\text { associated spirituality with the support gained from } \\
\text { her own experiences, friends and parents, and } \\
\text { highlighted its importance for a person's professional } \\
\text { development. }\end{array}$ & Laoxiang \\
\hline & & $\begin{array}{l}\text { "Some programs were about Yue's emperor Goujian and the } \\
\text { beauty Xishi, who washed her silk in the river. They are related } \\
\text { to our history and traditions. I love to watch the figures, } \\
\text { costumes, make-ups and decorations in the opera. I feel China is } \\
\text { a graceful nation. I really love opera." }\end{array}$ & Boshi linked it to the Chinese art and tradition. & Boshi \\
\hline & $\begin{array}{l}\text { Spiritual care } \\
\text { Identifying spiritual } \\
\text { needs }\end{array}$ & $\begin{array}{l}\text { "Therefore, I think if Chinese people are hospitalized in the UK, } \\
\text { the majority of them have no awareness of spiritual care, nor } \\
\text { expectations about the level of spiritual care.... they lower their } \\
\text { standards to a very basic level. Their key issue is about medical } \\
\text { treatment, getting a clear diagnosis, and getting treatment." }\end{array}$ & $\begin{array}{l}\text { Laoxiang explained that patients from Chinese } \\
\text { backgrounds appear to have limited awareness and } \\
\text { low expectations about receiving spiritual care due to } \\
\text { their focus on medical treatment. }\end{array}$ & Laoxiang \\
\hline & \multirow{3}{*}{ Communication } & $\begin{array}{l}\text { "Spiritual care is surely about communication, rather than } \\
\text { administrating medicine and something else." }\end{array}$ & $\begin{array}{l}\text { Yisheng mentioned that his understanding of spiritual } \\
\text { care was good communication. }\end{array}$ & Yisheng \\
\hline & & $\begin{array}{l}\text { "Yes, in terms of acceptance (spiritual care), clients are described } \\
\text { as emotionally unstable rather than having mental illness. } \\
\text { Using a different expression." }\end{array}$ & $\begin{array}{l}\text { Xuezhe stated that communication in spiritual care is } \\
\text { that healthcare professionals and nurses use words } \\
\text { that are appropriate and respectful. For example, using } \\
\text { different terms for "spiritual care" in Chinese rather } \\
\text { than jingshen huli (精神护理). }\end{array}$ & Xuezhe \\
\hline & & $\begin{array}{l}\text { "They have not talked to me about it, may be because we cannot } \\
\text { speak English ... I did not know what a kidney dialysis was. } \\
\text { Was it painful? Was it calm during the procedure? Nurses said } \\
\text { nothing to me." }\end{array}$ & $\begin{array}{l}\text { Youhao demonstrated that hospitals lack interpreting } \\
\text { services, stressing how this may impact her when } \\
\text { addressing her understanding of spirituality. }\end{array}$ & Youhao \\
\hline
\end{tabular}


Table 3. Cont.

\begin{tabular}{|c|c|c|c|c|}
\hline Category & Sub-Category & Extract & Authors' Explanation & Participant \\
\hline \multirow{4}{*}{ Support } & Care with love & $\begin{array}{l}\text { "She treats me as a close friend. As I feel she is isolated, I go to } \\
\text { her room every day, asking her what she wants to eat and does } \\
\text { she need a wash or a turn. She is still very close to me even } \\
\text { though she cannot understand why." }\end{array}$ & $\begin{array}{l}\text { Qinlao associated spiritual care with visiting patients } \\
\text { frequently. }\end{array}$ & Qinlao \\
\hline & \multirow{3}{*}{ Religious care } & $\begin{array}{l}\text { "If your topic approaches the religious dimension, you may } \\
\text { suggest that several chaplaincy services be set up in the mental } \\
\text { hospital." }\end{array}$ & $\begin{array}{l}\text { Xuezhe added that spiritual care was mainly the } \\
\text { responsibility of the hospital chaplaincy service, } \\
\text { suggesting nurses may invite services to provide } \\
\text { religious care. }\end{array}$ & Xuezhe \\
\hline & & $\begin{array}{l}\text { "In the hospitals there are some facilities or places for people } \\
\text { with different religions, such as Catholics, Muslims, and } \\
\text { Christians, to practice their religious activities, such as praying, } \\
\text { etc...." }\end{array}$ & $\begin{array}{l}\text { Laoxiang illustrated that spiritual care relates to the } \\
\text { facilities and places in hospital, such as a chapel or } \\
\text { mosque, meaning nurses can arrange religious care to } \\
\text { use these facilities. }\end{array}$ & Laoxiang \\
\hline & & $\begin{array}{l}\text { "... there are taboos in these religions. Some religions are very } \\
\text { confidential and cautious about their bodies, and permission } \\
\text { must be gained ... nurses must be clear about it by asking in } \\
\text { terms of nursing care." }\end{array}$ & $\begin{array}{l}\text { Chengshi offered that nurse needs to have religious } \\
\text { knowledge to address spiritual care. }\end{array}$ & Chengshi \\
\hline \multirow{3}{*}{$\begin{array}{l}\text { Maintaining standard } \\
\text { values }\end{array}$} & \multirow{3}{*}{ Chinese culture } & $\begin{array}{l}\text { "I tell my children that they should take care of their parents } \\
\text { when we are too old to move and care for ourselves. As for } \\
\text { myself, I left my parents when I was very young and cannot } \\
\text { take care of them myself now." }\end{array}$ & $\begin{array}{l}\text { Aiwa highlighted filial piety in her understanding of } \\
\text { spirituality and spiritual care. }\end{array}$ & Aiwa \\
\hline & & $\begin{array}{l}\text { "We worship souls and Buddha at festive times and the New } \\
\text { Year, with incense burnt and sacrifices offered." }\end{array}$ & $\begin{array}{l}\text { Maipian also related spirituality to the tradition of } \\
\text { worshipping Buddha in Buddhism and souls in } \\
\text { Daoism. }\end{array}$ & Maipian \\
\hline & & $\begin{array}{l}\text { "I have become old and do not think too much about spirituality. } \\
\text { What I am doing is shopping, cooking, eating, and sleeping. } \\
\text { Sometimes, I visit friends and we chit-chat." }\end{array}$ & $\begin{array}{l}\text { Qiangiian stated that he adapts to the retired life, when } \\
\text { addressing spirituality, knowing that ageing is the } \\
\text { natural process of life. }\end{array}$ & Qianjian \\
\hline
\end{tabular}


Table 3. Cont.

\begin{tabular}{|c|c|c|c|c|}
\hline Category & Sub-Category & Extract & Authors' Explanation & Participant \\
\hline \multirow[b]{2}{*}{$\begin{array}{l}\text { Maintaining standard } \\
\text { values }\end{array}$} & \multirow[b]{2}{*}{ Religion } & "I believe in the existence of God of Christianity." & Azhen claimed she is a Christian. & Azhen \\
\hline & & $\begin{array}{l}\text { "We are very faithful to our founder of religion, the person we } \\
\text { pray to, who predicted many years ago that food for future } \\
\text { human beings would not be as healthy and organic as it was } \\
\text { before (due to the use of pesticides and high technology such as } \\
\text { genetically modified food)." }\end{array}$ & $\begin{array}{l}\text { Xieguang highlighted the benefit of the religious } \\
\text { founder's thoughts for human beings. }\end{array}$ & Xieguang \\
\hline \multirow{6}{*}{$\begin{array}{l}\text { Achieving a } \\
\text { meaningful life }\end{array}$} & \multirow{2}{*}{ Happiness } & $\begin{array}{l}\text { "However, people who are not intellectuals think that playing } \\
\text { Majiang (麻将, a Chinese gambling where the loser needs to pay } \\
\text { a certain amount of cash to the winner) is a kind of activity in } \\
\text { spirituality." }\end{array}$ & $\begin{array}{l}\text { Xuezhe expressed that spirituality was recreational } \\
\text { activities to help individuals live a happy life. }\end{array}$ & Xuezhe \\
\hline & & $\begin{array}{l}\text { "I have a lovely grandson. He is my spiritual support. He chats } \\
\text { with me by video and they send his photos to me every two or } \\
\text { three days. The child is very lovely and is } 21 \text { months now." } \\
\text { (Spoken cheerfully.) }\end{array}$ & $\begin{array}{l}\text { Shufa said that spirituality was being together with her } \\
\text { grandson and proud of being a grandma. }\end{array}$ & Shufa \\
\hline & \multirow[t]{2}{*}{ Driving forces } & $\begin{array}{l}\text { "Spirituality } \ldots \text { is about being healthy and mentally vitalised } \\
\ldots \text { " }\end{array}$ & $\begin{array}{l}\text { Xieguang stated that spirituality was being vibrant } \\
\text { and energetic. }\end{array}$ & Xieguang \\
\hline & & $\begin{array}{l}\text { "You can use jingshen (精神 spirituality) for being in good spirits } \\
\text { (jingshenhao精神好)." }\end{array}$ & Xiaojin stated that spirituality was being high in spirit. & Xiaojin \\
\hline & \multirow[t]{2}{*}{ Essence and nature } & $\begin{array}{l}\text { "Spirituality is the true nature. Its origin is good. After we have } \\
\text { attained the Dao (the nature's way in Daoism), we know ... } \\
\text { what do to change ourselves." }\end{array}$ & $\begin{array}{l}\text { Maowai pointed out that spirituality was the true } \\
\text { nature by explaining how to gain this kind of nature. }\end{array}$ & Maowai \\
\hline & & "Spirituality is a trust of human nature ... a trust in humanity." & $\begin{array}{l}\text { Laoxiang expressed that spirituality was the trust of } \\
\text { human nature and humanity in society. }\end{array}$ & Laoxiang \\
\hline
\end{tabular}


Table 3. Cont.

\begin{tabular}{|c|c|c|c|c|}
\hline Category & Sub-Category & Extract & Authors' Explanation & Participant \\
\hline \multirow{2}{*}{ Relationships } & & $\begin{array}{l}\text { "I will not worry, and let things go with nature and be obedient } \\
\text { to Heaven if I have done my best." }\end{array}$ & $\begin{array}{l}\text { Sandi pointed out that spirituality was doing things } \\
\text { with the heart and trying one's best, having a good } \\
\text { relationship with herself. }\end{array}$ & Sandi \\
\hline & & “She (wife) looks after me." (Smiled.) & $\begin{array}{l}\text { Maoge was proud that he was being taken care of by } \\
\text { his wife, when addressing spirituality. }\end{array}$ & Maoge \\
\hline \multirow{3}{*}{$\begin{array}{l}\text { Perceptions of } \\
\text { spirituality }\end{array}$} & & $\begin{array}{l}\text { "If ... (speaking in a non-cohesive manner) must have mental } \\
\text { illness." (Stuttered.) }\end{array}$ & Kunan stuttered when explaining the term. & Kunan \\
\hline & & $\begin{array}{l}\text { "I think spirituality is not a direct translation for the word } \\
\text { jingshen (精神). I am not very clear on the definition of jingshen } \\
\text { (精神). However, spirituality is a more narrowly defined concept } \\
\text { to me. I cannot adequately address what jingshen (精神) is." }\end{array}$ & $\begin{array}{l}\text { Xiaojin stated that translating spirituality to jingshen in } \\
\text { Chinese was problematic. }\end{array}$ & Xiaojin \\
\hline & & $\begin{array}{l}\text { "This is a very personal issue and it is beyond many others' } \\
\text { consideration. How can you share your meaning of life ... ? I } \\
\text { cannot open my meaning of life to the public." }\end{array}$ & $\begin{array}{l}\text { Xuezhe explained that spirituality in terms of life } \\
\text { meanings was a personal issue. }\end{array}$ & Xuezhe \\
\hline
\end{tabular}




\subsection{Motivation}

The motivation found in this category emerged from the data, indicating situations where participants felt they were encouraged to pursue the search for a meaningful life. This could be through experiences of suffering, needs and hopes for a better life. Participants related these experiences to their understanding of spirituality and spiritual care.

\subsubsection{Suffering}

Social suffering was articulated by participants who had encountered cultural barriers while living in England. Dianxin said he has been unable to adapt to the differences between Eastern and Western culture and get involved in mainstream society, leading to feelings of helplessness,

" ... the old generation cannot involve themselves in the community. They feel helpless and their spirituality is depressed."

Individual reasons for suffering included participants' health (Maoge in Table 3), problems arising from the family (Aiwa), and the personal desire for materials or services (Qinlao).

Situations of suffering could inspire participants to improve themselves, for example, reflecting on Mencius' (an Ancient Chinese philosopher) saying that one's suffering is Heaven's will (Pengchao), and be appreciative of life. However, suffering could also result in people losing control and being in a state of shock, leading to risk-taking behaviors such as gambling. For example, Yisheng stated a suffering person overwhelmed with serious problems could fall into a state of shock, and Boshi said persistent suffering could lead the ethnic Chinese to gamble.

"However, the majority of people are not in the same way (to cope), and they are overwhelmed by a serious situation, such as cancer. Their brain suddenly goes blank and they do not know how to deal with it." (Yisheng)

"This is depression. They have to deny themselves. The more denials, the more depression. Many Chinese here suffer from depression and they turn to gamble ... " (Boshi)

\subsubsection{Need}

Participants' need for health, safety, family closeness and community support also encouraged them to seek greater life accomplishments. Some emphasized a single dimension of need regarding spirituality, such as basic material necessities in their daily lives, for example, a sustainable profession, income (Sandi), clothes or money (Dianxin), or psychological needs such as good family support (Maipian), love from family members (Qinlao), social support (Dianxin see Table 3), or a general sense of accomplishment (Maowai). For example, Dianxin stressed that food and money were important to people's spirituality, Maipain highlighted that he needs family and talking to the family can ease his loneliness abroad, and Qinlao explained that patients need family to be with them, particularly at the end of their lives.

"People in the past cherished money and clothes. They used to say if they have money, they could eat better and wear better." (Dianxin)

"In the UK, I do not have spiritual needs. I am alone. I can only communicate with the family and they can support me sometimes." (Maipain)

"At the end of life, patients need to feel comfortable. If the family comfort and talk to them, they will come to be relaxed from this sort of spiritual care." (Qinlao)

Some incorporated the need for psychological contentment and self-fulfillment into their understanding of spirituality and spiritual care. For example, Boshi said

"Sometimes we need psychological love and care. We also need to enjoy the spiritual contentment by helping others." 


\subsubsection{Hope}

A motivating source for a meaningful life also came from participants' hopes. In this study, when explaining spirituality, participants' hope could be their normal wish for good health and being safe (Azhen), or a willingness to gain one's life purpose, or a life pursuit deep in one's heart that a person desires (Mimang). For example, Qiangjian showed that spirituality and spiritual care were the hope of being healthy, and Qinlao stated spirituality was a person's will,

"I wish a good mental alertness, physically healthy, be careful to avoid slip and fall." (Qiangjian)

"Spirituality is soul and will, soul and will for life." (Qinlao)

Similar to the concept of need, what participants hoped for is like what they needed in their understanding of spirituality and spiritual care. The two concepts were complementary, providing a deeper level of understanding of spirituality by highlighting the different dimensions and shared components. For example, family closeness was highlighted as a common need, while the hope of filial devotion was something participants yearned for.

\subsection{Support}

Important to the process of seeking a meaningful life, category support was the situations in which participants felt supported. Supporting resources included spiritual resource in their everyday life and spiritual care provided by nurses and healthcare staff in a healthcare context and participants related these to their notions of spirituality.

\subsubsection{Spiritual Resources and Spiritual Care}

Spiritual resources could come from one's family, their own thoughts (Laoxiang) and beliefs, Chinese cultural philosophies and art (Boshi). Spiritual care for patients means identifying spiritual needs, communication and caring with love and religious care.

Identifying Spiritual Needs

In terms of identifying spiritual needs, this included staff asking patients if they had any specific religious needs, asking directly about religious requirements and obtaining consent to refer patients to a religious leader in a formal or informal assessment. For example, Qinlao, a nurse noted:

"In the admission process, we already ... nurses have already assessed patients' spiritual needs by asking the question, "do you need religious support?" If they said yes, we would arrange this."

Participants' spiritual needs included for family and health staff support when ill, such as encouragement, accompanying them and being there to listen to them. Mimang related spiritual care to the service and support from family, friends and healthcare professionals.

"During the illness, a patient needs strong belief and confidence to help him come through the disaster. He needs a listener to listen to the suffering inside him, as well as supporting strength which can come either from relatives or friends, or the physician."

Identifying these needs requires nurses and healthcare professionals to be attentive and intuitive because ethnic Chinese may not necessarily provide the information from a direct question. Participants also indicated that it was important for nurses and healthcare professionals to respond quickly and appropriately to patients' spiritual needs, although their awareness of these needs may be limited due to their focus being on the provision of medical treatment (Laoxiang). Low awareness of their spiritual needs could also be due to cultural or personal barriers, as ethnic Chinese may not be forthcoming about their religious beliefs. This was demonstrated by participants having difficulty choosing an answer, providing contradictory information, or answering "Atheist" when asked to complete a demographic form after the interview. One participant, Shufa, indicated she was an atheist but connected spirituality with support from heaven. The concept of heaven can be understood as God in Chinese culture. 
"Yes, that is the reason I do not have resentment. You know, Heaven is very good to me and lets me survive."

\section{Communication}

Participants also related spiritual care to communication (Yisheng, see Table 3). This included timely support with regard to interpreting patients, and healthcare professionals' good communication skills, for example, being humorous and pleasant, building trusting relationships with patients, following the patient's pace in speaking, and speaking with clarity. As exemplified, Shufa stated that a timely interpretation service was important to ethnic Chinese in the hospital. Maowai noted that having a sense of humor and speaking pleasantly enhanced communication and established a harmonious relationship between him and staff. Mimang explained that the pace of conversation was an important requirement of clear communication.

"It could be better if an interpreter was accessible at whatever time... people who do not understand English has no way to contact others. Having an interpreter is important." (Shufa)

"One doctor who speaks Mandarin and Cantonese interpreted for us. He joked with my husband, 'You are sick for a long time and you have such a speedy recovery after the operation'." (Maowai)

"Spiritual care is about the staff's speaking pace. Some talk very fast and patients cannot understand. It would be better if they can slow down ... Speaking clearly would be good." (Mimang)

Participants also viewed spiritual care as using respectful words and avoiding disputed terms such as jingshen huli (精神护理, psychiatric nursing) to reduce patients' feelings of being discriminated against (Xuezhe). Spiritual care, when translated as jingshen huli in Chinese, could be considered as an indicator of mental problems. For participants, good communication meant speaking with love and sincerity (Qinlao). Many described the shortage of professional interpreting services, emphasizing the negative impact of this on patients and their health (Youhao), and suggested enhancing the interpreting service by using family or ethnic Chinese staff (Linde).

"I talk to patients I met in the hospital. I also touch or hug them if they are sad and asking questions such as, saying 'What happened', 'Could I help?'." (Qinlao)

"We used to let the family be our interpreters but they are not allowed now. We must use a professional interpreter instead." (Linde)

Caring with Love

Participants equated spiritual care to care with love, suggesting that healthcare professionals should show love and kindness when providing spiritual care, especially for the frail and dying. This included close and frequent contact with the patient (Qinlao), spending time with them, being sincere, withholding bad news from a frail or dying patient, using respectful terms and respecting patients and their wishes. For example, Laoxiang described her understanding of spiritual care as kindness, love and behavior that touches people's hearts. Wangxing explained it as a dying person only needs compassion and empathy during his or her final journey. Yisheng related spiritual care to treating patients sincerely.

"I know an English man who has had a voluntary job for 10 years. His job involves transporting the frail people in a wheelchair and pushing them to a little chapel at the ward in the afternoon once a week... This is typical spiritual care for patients." (Laoxiang)

"When a person is dying, you can accompany him and show your enormous compassion to him, because he has very limited time left. During this special period of dying, the love to him ... it will be very much appreciated if there is such kind organization in our society." (Wangxing) 
"How to provide spiritual care is beyond my knowledge. I think it might be ... the key is enlightening the patient with reason and emotionally moving him, which is about treating him honestly." (Yisheng)

\section{Religious Care}

When expressing spirituality and spiritual care, participants also mentioned religious care, which was seen as the joint responsibility of chaplaincy services, nurses and other healthcare professionals in the hospital. Qinlao directedly related spiritual care to religious care and explained that it was beneficial for patients' well-being, particularly in providing them with a peaceful feeling at the end-of-life stage.

"Religious care is very important and I really like it ... because when patients die they are not frightened. They will think they are going to another land, and to die is just to move their house (to another place and) join another family. Therefore, they are not frightened ... they die in peace... I think spiritual care is very important."

Xuezhe suggested that nurses could facilitate religious care by inviting the chaplaincy services to provide religious care. Laoxiang suggested help in arranging private spaces for personal prayer and places for religious activities. Chengshi felt that nurses needed to gain knowledge of major religions and cultures to understand, for example, what is prohibited, in order to provide appropriate spiritual care (see Table 3). Participants also linked religious care to support gained from friends and community pastors. Dianxin explained that spiritual care was inviting the community pastor and friends to support patients,

"If the patient is a Christian, we will arrange for the pastor from the church, together with the church members, to visit him and pray for him in the hospital."

\subsection{Maintaining Standard Values}

When seeking life meaning, maintaining standard values emerged as the actions or activities used by participants. This element consisted of two sub-categories, Chinese culture and religion, which were important in participants' descriptions about spirituality and spiritual care.

\subsubsection{Chinese Culture}

Chinese culture included philosophical ideas from Confucianism, Buddhism and Daoism, using the philosophical figures, traditions, thoughts and values in the expression of spirituality and spiritual care. Confucian philosophy embraced family responsibility, filial piety (Aiwa), ancestor worship, keeping a balanced mind and being genuine to reach self-perfection to fulfil a better social and family role. Buddhism involved Buddhist customs, figures and thoughts, such as Chaodu (pacification of the dead), worshipping Buddha (Maipian), applying the concept of Karma, and ideas about true nature, tolerance of suffering, letting go and forgiving. In terms of Daoist principles, the important elements were Daoist figures such as celestial beings, empowered historical figures or empowered ancestors, and the traditions for worshipping these philosophical figures (Maipian). The Daoist principle of wuwei, non-doing and non-action in English, was also mentioned, highlighting the importance of inner peace, quietness and following the natural process of life and daily living (Qiangjian) from Chinese culture.

\subsubsection{Religion}

Participants also associated spirituality and spiritual care with religion and religious values guiding them to find life's meaning. Spirituality was seen as adhering to a religious faith (Azhen), practicing the religion through praying and going to religious places, or benefitting from a certain religion (Xieguang). Participants demonstrated a lack of a distinct boundary between religion and Chinese culture, as some values could be understood as either religious or cultural terms. For example, in this study, filial piety was understood as a cultural tradition which is appreciated in Chinese society but was also noted as an 
important teaching in Confucianism to establish a successful family, and to be grateful to one's parents in Buddhism from a religious understanding.

\subsection{Achieving a Meaningful Life}

In the process of seeking a meaningful life, achieving this state emerged as an outcome of people holding to their values and personal beliefs. It consisted of three sub-categories, happiness, driving forces and the essence and nature of life, demonstrating that being happy, vibrant and realizing the essence of life were, for participants, part of pursuing life's meaning in their understanding of spirituality.

\subsubsection{Happiness}

Happiness in this study was interpreted as a pleasant state or the noticeable contentment participants gained from certain experiences. It is people's common feeling of being content in terms of achieving life meanings. Some participants associated spirituality with happiness, describing it as good moods and a positive outlook. They also related spirituality and spiritual care to the activities or methods making oneself happy, and to the impact of remaining happy in order to live meaningful life. For example, Xuezhe associated the terms with the recreational activity of the majiang game, providing him with a happy life. Shufa and Dianxin linked them to being together with the family and having a sense of values. Kunan explained spirituality as having sufficient welfare support for old people's daily living.

"One main reason I am happy is that my parents and siblings are all in the UK." (Dianxin)

"We have welfare payment as well as pension ... everything is sufficient (speaks with smile and satisfaction)." (Kunan)

\subsubsection{Driving Force}

As well as the pleasant moods and contented feelings which were participants' common experiences, they also described spirituality as a kind of driving force from an abstract standpoint, as invisible forces within the human body. For example, Shuaige compared spirituality in humans to the driving force of an engine, empowering individuals to live a life filled with meaning. Xieguang stated that spirituality was being vibrant and energetic, while Xiaojin connected it to jingshen hao (精神好) in Chinese, which means being in high spirits. In terms of spirituality, the driving forces can be seen as a higher level of achievement in gaining one's life meaning because it is driven energy that enables people to have contentment and be happy.

\subsubsection{Essence and Nature}

Spirituality was also regarded as the essence and nature of humans. For example, Shuiage described spirituality as the essential part inside a person, while Maowai depicted it as the true nature with its attribute and benefit when addressing her understanding of spirituality (see Table 3). Similarly, Aiwa noted that spirituality had a stable nature that is resistant to changes.

"A person's nature is very difficult to change unless he has suffered substantial setbacks."

Laoxiang, when discussing spirituality, extended the idea of human nature to trusting in oneself and humanity. Understanding spirituality as an essence and nature reflects the ultimate achievement in realizing one's life meaning because this entity is closely linked to the driving force described above and is perceived as an ultimate pure and virtuous entity which may be beyond common people's experiences.

\section{Supporting Factors: Relationships and Perceptions of Spirituality}

Participants' relationships with others and perceptions of spirituality can influence the above process (see Figure 1). 


\subsection{Relationships}

The category of relationships emerged as a supporting factor for individuals seeking their life meanings. Participants connected spirituality with the self, the family, Higher Beings, society and others creatures and nature. According to Boshi:

"Our spirituality craves harmonious relationships among people, between human beings and our natural environment, in addition to that between human beings and God".

These different relationships can determine how individuals seek their life meanings. For instance, Sandi focused on her relationship with herself, emphasizing that spirituality was about self-development for her. On the other hand, Maoge related spirituality to contentment with family relationships. Focusing on transcendence, Xieguang explained that spirituality was the relationship between human and spirit.

"Human and spirits are in the different dimensions of the same space. We can live together harmoniously."

\subsection{Perceptions of Spirituality}

In this study, perceptions of spirituality was another factor influencing individual attempts to seek life meaning. Spirituality and spiritual care were considered terms difficult to articulate, being broad and abstract in nature as well as sometimes very private and personal. There was potential for confusion when the Chinese equivalents of jingshen and jingshen huli were applied. Azhen noted that it was a difficult concept to articulate, because participants would describe it using material terms, which is contrary to spirituality.

"Spirituality is very difficult to vindicate."

The abstract nature of spirituality meant that Shuaige did not give it much thought.

"I rarely consider it."

Azhen also indicated that spirituality was open to individual explanations as different people had different understandings. Laoxiang noted that the understanding of spirituality can change over time. The topic of spirituality can also be perceived broadly, as indicated by Heping, who felt that spiritual care was holistic, covering physical, psychological and cultural care.

"Everyone has a different feeling for it." (Azhen)

"He will then keep having different perceptions on the spiritual dimension. He will feel his pursuit is changing at different times, and feel the things he cannot acquire are more important. As a result of this, he cannot grasp the direction of life." (Laoxiang)

"Holistic, I will talk about something which is holistic. At first, holistic care is surely about whether a patient suffers from pain physically. Then, it is about considering his psychological experiences and his physiology. This also includes his specific cultural background, language and social status." (Heping)

The abstract, subjective and broad nature of spirituality presented a translating issue between spirituality and jingshen in Chinese, as demonstrated by Xiaojin, who said that translating the word spirituality into jingshen was incorrect. Xuezhe considered that spirituality was an important and personal topic, and that to ask questions about spirituality was to explore deeply personal questions, and thus it is a sensitive subject.

In this study, participants' descriptions of spirituality and spiritual care were very similar and they tended to use the terms interchangeably.

\section{Discussion}

In this investigation, 25 ethnic Chinese participants aged from 20 to 80 years residing in the UK provided their understanding of spirituality and spiritual care and they integrated the terms into a life meaning-seeking process. The process shows that when inspired in a suffering situation and supported by healthcare professionals and family, ethnic Chinese residing in England generally adhere to Chinese cultural and religious values to find their life meanings. Seeking a meaningful life proves the current understanding in the UK that spirituality is a dynamic dimension of human life relating to the way people experience 
and seek meanings and purpose, and the way they connected to the moment (European Association for Palliative Care n.d.). It emphasizes Chinese cultural and religious values in the participants' understanding of the term.

In the following, the three points, seeking a meaningful life, suffering and physical health, were discussed to show their relevance to practice, education, research and policy makers in the field of healthcare and nursing.

\subsection{Seeking a Meaningful Life Process}

In this study, seeking a meaningful life related specifically to participants' understanding of spirituality. This verifies the existing definitions that spirituality can be understood as finding life meanings (Puchalski et al. 2014; Weathers et al. 2016). The importance of finding the meaning of life in spirituality is in line with Rosyidah et al.'s (2018) study in which, for cancer patients in Indonesia, spiritual coping was to find the meaning of life through establishing a relationship with religion and God in either Christianity or Islam, thus making it applicable to patients with religious faith. In comparison, however, this study highlights aspects of spirituality and spiritual care as being integrated into the process of seeking a meaningful life from a cultural and religious perspective, with implications for the Chinese immigrants who were deeply influenced by Chinese cultural and religious beliefs. Nurses and healthcare professionals could apply this to their implementation of spiritual care for ethnic Chinese in UK healthcare settings by looking for motivating and supporting situations, the values they hold, and what life means to them.

\subsection{Suffering as Motivation to Seek Better Life Purpose}

Some participants related their understanding of spirituality and spiritual care to suffering, which was their motivation to follow Chinese cultural and religious traditions for a meaningful life. This is reflected in Gomes et al.'s (2019) study that found that spirituality among patients with sickle cell disease was motivated by their fear of death, and they used different kinds of religious rituals to cope with the fear. However, in the current study, participants associated spirituality with a broad range of suffering in terms of health, family and social issues, and used Chinese cultural values to cope with the difficulties encountered. One reason for this may be the Chinese view that life is full of suffering, occurring in birth, ageing, illness and death, according to the Buddhist tradition, or that suffering is the payment for wrongdoing, as a part of maintaining the balance of nature or as something one accepts as heaven's or nature's rule in Buddhism, Daoism and Confucianism (Niu et al. 2021b). Such views may lead to ethnic Chinese accepting, tolerating, and working hard when experiencing suffering. An understanding of this response and reason for suffering may be helpful for healthcare workers in implementing culturally congruent spiritual care for ethnic Chinese. Policy makers' guidelines for spiritual care could also emphasize the importance of understanding in how people view that the concept of suffering. Understanding how suffering is perceived among ethnic Chinese could help educators to include these concepts in their teaching materials, because this can help nurses or students understand how ethnic Chinese perceive suffering. For example, understanding the Chinese tendency of tolerating and hiding suffering can help nurses identify their needs on time.

\subsection{Illness in Suffering}

Participants linked spirituality and spiritual care to aspects of physical, psychological and social health, specifically focusing on physical illness. This is reflected in the work of Sun-Hwa et al. (2020) and Lewinson (2016), from the perspective of nursing students, that found that people's physical health was considered a priority in nurses' spiritual care plans in the hospitals of South Korea and the UK. In this study on spiritual care, participants highlighted the importance of physical care mainly from the healthcare user's perspective, equating spiritual care with physical care or physical health concerns in Chinese communities. This indicates putting patients' physical needs first as a spiritual 
care intervention is the consensus of health professionals, educators and healthcare users in both Western and Asian cultures. It also shows that physical care should be the first consideration when caring for patients in the hospital and other healthcare settings, then the subsequent focus should be on religious needs and spiritual care for both ethnic Chinese and other patients. However, in countries where spiritual care implementation is scarce, nursing researchers and policy makers could give some attention to the spiritual dimension of care rather than constantly focusing on physical and biological needs, which would help to ensure that nurses and healthcare professionals are better prepared to support people's spiritual needs.

\subsection{Limitations and Strength}

One limitation of this investigation lies in the broad research question that led to recruiting ethnic Chinese with diverse backgrounds, including those with and without hospitalization experience, and those out-patients still visiting doctors frequently at the time of being interviewed. Although this makes the emerging theory applicable to a wide range of Chinese ethnic groups in the UK, it presented a challenge because the findings were not patient-focused, and thus were not specific to spiritual care implemented for hospitalized patients. Future research might apply stricter inclusion criteria to explore the understanding of spirituality and spiritual care from the patients' perspective, making the findings more relevant to implementation in a hospital setting.

\section{Conclusions}

Following the grounded theory, this study explored ethnic Chinese thinking about spirituality and spiritual care while residing in England. This included the process of seeking a meaningful life; in situations of suffering, supported by healthcare professionals and family, ethnic Chinese tended to adhere to Chinese cultural and religious values to find life meaning, and their relationships with others and their perceptions of spirituality influence the way they do this.

\section{Implications for Nursing}

The findings have relevance for spiritual care practice, such as finding life meaning, understanding the Chinese way of perceiving suffering and prioritizing physical needs. For the process of finding life meanings in spiritual care, nurses could implement spiritual care for ethnic Chinese in the UK by looking for motivating reasons in suffering, need and hope. They could also pay attention to supporting factors of effective communication, identifying spiritual needs through both formal assessments and informal ones such as listening and being aware that being an atheist and of no religion may require a further assessment. Furthermore, nurses could be sensitive to the cultural and religious values that ethnic Chinese believe and observe whether gaining happiness is the driving force and essence their life purpose. Policy makers could incorporate the importance of seeking life meaning in policies relating to spiritual and religious care for ethnic Chinese and indeed other minority ethnic groups in the UK.

The findings have relevance to clinical practice if they apply this process, use sufferingrelated knowledge and prioritize physical illness in spiritual care practice. They also have implications for policy makers and educators in drawing up informed care guidelines and teaching materials for nursing and other healthcare professionals.

Author Contributions: Conceptualization, Y.N., W.M. and M.P.; methodology, Y.N.. W.M. and M.P.; software, Y.N.; validation, W.M. and M.P.; formal analysis, Y.N.; investigation, Y.N.; resources, Y.N.; data curation, Y.N..; writing-Y.N., W.M. and M.P.; supervision, W.M. and M.P.; All authors have read and agreed to the published version of the manuscript.

Funding: This research received no specific grant from any funding agency in the public, commercial, or not-for-profit sectors. 
Informed Consent Statement: Staffordshire University ethics committee approved the research project. Participants' informed consents were gained.

Data Availability Statement: This paper originates from Yanping NIU's PhD thesis which was a preprint published in Staffordshire university Staffordshire Online Repository (Niu 2019). The thesis can be traced from http://eprints.staffs.ac.uk/id/eprint/5765.

Acknowledgments: We thank all the participants who took part in this study and the administrators in the Chinese community centres who supported the recruitment of participants and allowed the use of their facilities to conduct our interviews.

Conflicts of Interest: No conflict of interest has been declared by the authors.

\section{References}

Balthip, Karnsunaphat, Wilfred McSherry, and Kittikorn Nilmanat. 2017. Spirituality and dignity of thai adolescents living with HIV. Religions 8: 257. [CrossRef]

Carson, Verna Benner, and Ruth Stoll. 2009. Spirituality defining the indefinable and reviewing its place in nursing. In Spiritual Dimensions of Nursing Practice. Edited by Verna Benner Carson and Harold G. Koenig. West Conshohocken: Templeton Press.

Chao, Co-Shi, Ching-Huey Chen, and Miaofen Yen. 2002. The essence of spirituality of terminally ill patients. Journal of Nursing Research 10: 237-45. [CrossRef] [PubMed]

Chen, Lih-Mih, Christine Miaskowski, Marylin Dodd, and Steven Pantilat. 2008. Concepts within the Chinese culture that influence the cancer pain experience. Cancer Nursing 31: 103-8. [CrossRef] [PubMed]

Chinese Academy of Social Science. 2016. Dictionary of Current Chinese [现代汉语词典], 7th ed. Beijing: The Commercial Press.

Clark, Lauren, Ana Sanchez Birkhead, Cecilia Fernandez, and Marlene J. Egger. 2017. A transcription and translation protocol for sensitive cross-cultural team research. Qualitative Health Research 27: 1751-64. [CrossRef] [PubMed]

Cooney, Adeline. 2011. Rigour and grounded theory. Nurse Researcher 18: 17-22. [CrossRef] [PubMed]

Corbin, Juliet M., and Anselm L. Strauss. 2015. Basics of Qualitative Research: Techniques and Procedures for Developing Grounded Theory. Los Angeles: SAGE.

de Vries, Kay, Elizabeth Banister, Karen Harrison Dening, and Bertha Ochieng. 2019. Advance care planning for older people: The influence of ethnicity, religiosity, spirituality and health literacy. Nursing Ethics 26: 1946-54. [CrossRef] [PubMed]

European Association for Palliative Care. n.d. EAPC Task Force on Spiritual Care in Palliative Care. Available online: https: //www.eapcnet.eu/eapc-groups/task-forces/spiritual-care (accessed on 6 October 2021).

Glenn, Chontay Taylor, and Barbara Pieper. 2019. Forgiveness and Spiritual Distress: Implications for Nursing. Journal of Christian Nursing 36: 185-89. [CrossRef] [PubMed]

Gomes, Maiara Vitor, Aline da Silva Gomes Xavier, Evanilda Souza de Santana Carvalho, Rosa Cândida Cordeiro, Sílvia Lúcia Ferreira, and Amarry Dantas Morbeck. 2019. "Waiting for a miracle": Spirituality/Religiosity in coping with sickle cell disease. Revista Brasileira de Enfermagem 72: 1554-61. [CrossRef] [PubMed]

GOV.UK. 2020. Chinese Ethnic Group: Facts and Figures. Available online: https://www.ethnicity-facts-figures.service.gov.uk/ summaries / chinese-ethnic-group\#population (accessed on 16 June 2021).

ICN. 2012. The ICN Code of Ethics for Nurses (Revised). International Council of Nurses . Available online: https:/ /www.icn.ch/ nursing-policy/regulation-and-education (accessed on 15 May 2020).

Lewinson, Lesline P. 2016. The Impact of Pre-Registration Nurses' Spirituality Education on Clinical Practice: A Grounded Theory Investigation. Ph.D. Thesis, Staffordshire University, Stoke-on-Trent, UK.

McSherry, Wilfred, Adam Boughey, and Josephine Attard, eds. 2021. Enhancing Nurses' and Midwives' Competence in Providing Spiritual Care: Through Innovative Education and Compassionate Care. Berlin/Heidelberg: Springer.

Mok, Esther, Frances Wong, and Daniel Wong. 2010. The meaning of spirituality and spiritual care among the Hong Kong Chinese terminally ill. Journal of Advanced Nursing 66: 360-70. [CrossRef] [PubMed]

Murray, Ruth Beckmann, and J. Judith Proctor Zentner. 1989. Nursing Concepts for Health Promotion. London: Prentice Hall.

Nair, Devika, Kemberlee Bonnet, Marcus G. Wild, Ebele M. Umeukeje, Rachel B. Fissell, Marquetta L. Faulkner, Nader S. Bahri, Marino A. Bruce, David G. Schlundt, Kenneth A. Wallston, and et al. 2021. Psychological adaptation to serious illness: A qualitative study of culturally diverse patients with advanced chronic kidney disease. Journal of Pain $\mathcal{E}$ Symptom Management 61: 32. [CrossRef]

Narayanasamy, Aru. 1999. A review of spirituality as applied to nursing. International Journal of Nursing Studies 36: 117-25. [CrossRef]

NHS Education for Scotland. 2009. Spiritual Care Matters: An Introductory Resource for All NHS Scotland Staff. Edinburgh: NHS Education for Scotland.

Niu, Yanping. 2019. Meaning and Experiences of Spirituality and Spiritual Care among People from Chinese Backgrounds Living in England: A Grounded Theory Investigation. Ph.D. Thesis, Staffordshire University, Stoke-on-Trent, UK. Available online: http:/ / eprints.staffs.ac.uk/id/eprint/5765 (accessed on 9 October 2021).

Niu, Yanping, Wilfred McSherry, and Martin Partridge. 2020. An understanding of spirituality and spiritual care among people from Chinese backgrounds: A grounded theory study. Journal of Advanced Nursing. [CrossRef] 
Niu, Yanping, Wilfred McSherry, and Martin Partridge. 2021a. The perceptions of spirituality and spiritual care among people from chinese backgrounds living in England: A grounded theory method. Journal of Transcultural Nursing 32: 350-59. [CrossRef] [PubMed]

Niu, Yanping, Wilfred McSherry, and Martin Partridge. 2021b. Exploring the meaning of spirituality and spiritual care in Chinese contexts: A scoping review. Journal of Religion and Health. [CrossRef]

Puchalski, Christina M., Robert J. Vitillo, Sharon K. Hull, and Nancy Reller. 2014. Improving the spiritual dimension of whole person care: Reaching national and international consensus. Journal of Palliative Medicine 17: 642-56. [CrossRef] [PubMed]

Rosyidah, Arafat, Ratna Sitorus, Mustikasari, and Majid Abd. 2018. Spiritual coping in people living with stroke. International Journal of Caring Sciences 11: 658-62.

Speed, Shaun, Zeyuan Sun, and Zhenmi Liu. 2021. A focus group study of older Chinese people with CVD patients in the North West of the UK. Prim Health Care Research Development 22: e24. [CrossRef] [PubMed]

Strauss, Anselm, and Juliet Corbin. 1998. Basics of Qualitative Research: Techniques and Procedures for Developing Grounded Theory, 2nd ed. Thousand Oaks: Sage Publications.

Sun-Hwa, Shin, Kim Hyeon-Young, Woo Hee-Yeong, Lee Myung-Nam, and Kim Ye-Jean. 2020. Content analysis of the meaning of spiritual care as perceived by nursing students. Korean Journal of Hospice E Palliative Care 23: 151-61. [CrossRef]

Swinton, John. 2010. The meaning of spirituality: A multiple-perspective approach to the 'spiritual'. In Spiritual Assessment in Healthcare Practice. Edited by Wilfred McSherry and Linda Ross. Keswick: M\&K Update Ltd.

Weathers, Elizabeth, Geraldine McCarthy, and Alice Coffey. 2016. Concept analysis of spirituality: An evolutionary approach. Nursing Forum 51: 79-96. [CrossRef] [PubMed]

Zhu, Junhong, and Frances Kam Yuet Wong. 2021. Chapter 9 Global case study in spirituality: Stories of hope from China. In Spiritual Dimensions of Advanced Practice Nursing. Edited by Melanie Rogers. Basingstoke: Springer Nature, in press. 